DOI: http://dx.doi.org/10.12660/gvcasosv7n2c14

\title{
SAÚTIL: UM SONHO EM UMA ENCRUZILHADA ${ }^{1}$ Saútil: a dream at a crosrroads
}

EDGARD BARKI - edgard.barki@gmail.com

Escola de Administração de Empresas de São Paulo da Fundação Getulio Vargas - São Paulo, SP, Brasil

\section{Resumo}

Ao longo de cinco anos, a Saútil testou diversos modelos de negócios: B2C, B2B e B2G. Nesse período, a empresa registrou um bom crescimento e tornou-se uma das estrelas de negócios de impacto no Brasil. No entanto, com a crise de 2014-2016, a empresa começou a sofrer bastante. Por meio do caso, os alunos poderão discutir os desafios de um empreendedor social que busca ter retorno financeiro e impacto social e as vantagens e desvantagens de um investimento em uma startup.

Palavras-chave: estratégia, negócios de impacto, startups

\begin{abstract}
Over the course of five years, Saútil has tested several business models: B2C, B2B and B2G. During this period, the company registered a formidable growth and became one of the most well known impact businesses in Brazil. However, with the crisis of 2014-2016, the company began to suffer. Through this case, students shall discuss the challenges of a social business seeking both financial return and social impact, and the advantages and disadvantages of investing in a startup.
\end{abstract}

Keywords: strategy, impact businesses, startups

Era a última reunião do ano de 2016 e, provavelmente, uma das mais decisivas daquela dupla de sócios que começou com um sonho, em junho de 2010, tornou-se uma das maiores apostas de empreendedorismo social em 2013 e, agora, estava em uma encruzilhada.

Fernando Fernandes e Edgard Morato haviam formado uma boa dupla com sua complementariedade. Fernandes era médico, metódico, planejador. Morato era designer, criativo, sonhador. Juntos, haviam criado, em 2011, a Saútil, um negócio de impacto que tinha como sonho diminuir a falta de informação da população de mais baixa renda sobre serviços de saúde.

Depois de várias mudanças no modelo de negócios nos últimos cinco anos, uma passagem pela principal aceleradora de negócios de impacto do Brasil e um investimento recebido do principal fundo de investimento de impacto social no Brasil, os sócios debatiam sobre qual seria o futuro deles: vender a empresa, tentar continuar com as próprias pernas ou simplesmente fechar a empresa.

\section{O embrião da Saútil}

Em sua experiência como médico, Fernando percebia a dificuldade de os cidadãos acessarem os serviços básicos de saúde por falta de informação. Ele sabia que era possível criar uma plataforma que ajudasse as pessoas a encontrarem, de maneira simples e rápida, os recursos de saúde disponibilizados pelo SUS na cidade.

${ }^{1}$ A elaboração deste caso contou com apoio financeiro do Instituto de Cidadania Empresarial (ICE). 
Inconformado com as dificuldades dos cidadãos, em janeiro de 2011, Fernando associou-se a Edgard, dono de uma agência de comunicação que já prestava serviços a Fernando. Com o sonho de desenvolver um projeto que facilitasse a vida dos usuários do SUS, e a ideia de Morato de criar um buscador de saúde gratuito, os dois abriram uma Sociedade de Conta Participação ${ }^{2}$ (SCP), como um projeto social.

Com uma SCP, era possível abrir uma conta bancária, sem a burocracia da abertura de uma empresa. No início, era apenas um projeto paralelo às atividades que os dois já exerciam, mas que logo começou a ter muitos acessos, demonstrando a necessidade da população por esse serviço. Em quatro meses e sem nenhum esforço de comunicação, a organização teve 40 mil acessos. Com esse sucesso inicial, os empreendedores perceberam que tinham uma oportunidade de negócios e decidiram abrir uma empresa.

O conceito do buscador, sua inovação e relevância para a população que depende do SUS fizeram com que a Artemisia (principal aceleradora de negócios de impacto do Brasil) e outros atores do ecossistema de negócios de impacto ficassem logo interessados. Assim, já em agosto de 2011, a Saútil começou o processo de aceleração com a Artemisia para melhor definir seu modelo de negócios e conseguir acessar uma rede relevante de mentores, investidores e outros interessados.

\section{Definindo um modelo de receitas}

No Brasil, é muito difícil para um cidadão obter informação de onde poderia encontrar um posto de saúde que resolvesse o seu problema específico ou para saber se teria direito a remédios mais baratos ou eventualmente gratuitos. Os sites dos Governos Federal, Estadual e Municipal são confusos e de difícil acesso. A plataforma da Saútil, ao contrário, era simples e facilitava muito a vida do cidadão.

Assim, o impacto social da Saútil estava claro: diminuir a assimetria de informação para os usuários do SUS que não sabiam de seus benefícios e que também tinham dificuldade de identificar onde podiam ser atendidos. Os depoimentos de dois usuários deixam bem claros esses benefícios:

Ajudaram e muito, pois tenho comprado esse medicamento, e não sabia que tinha direito pelo SUS. Agora vou fazer os procedimentos necessários. (José Roberto)

Foi bem mais fácil tanto localizar como saber os postos de saúde mais próximos e que possuíam o medicamento que eu precisava, além de esclarecer se esse medicamento era ou não distribuído gratuitamente. (Lauro)

No entanto, a questão estava em como monetizar esse serviço. A primeira alternativa pensada pelos sócios foi buscar patrocínios para a plataforma, tendo em vista seus milhares de acessos. Já no início de 2012, a empresa conseguiu alguns patrocínios.

Nesse momento, o primeiro fundo de investimento de negócios de impacto no Brasil (Vox Capital) começou a se interessar pela Saútil e, já em março de 2012, fez um aporte de R \$ 50 mil para a empresa, como investimento retornável. Grande parte desse recurso foi utilizado em comunicação no Google, para alavancar o número de acessos ao site. O negócio começava a ganhar fôlego para crescer, e dois novos sócios minoritários incorporaram-se à Saútil.

O processo de aceleração com a Artemisia deixou claro que o modelo de patrocínio teria muita dificuldade de sucesso no longo prazo. Assim, buscaram-se alternativas. Para tanto, os sócios

\footnotetext{
${ }^{2}$ SCP: quando duas ou mais pessoas, sendo ao menos uma comerciante, se reúnem, sem firma social, para lucro comum, em uma ou mais operações de comércio determinadas, trabalhando um, alguns ou todos em seu nome individual para o fim social; a associação toma o nome de sociedade em conta de participação, acidental, momentânea ou anônima; essa sociedade não está sujeita às formalidades prescritas para a formação das outras sociedades, e pode provar-se por todo gênero de provas admitidas nos contratos comerciais. Fonte: http://www.portaltributario.com.br/guia/scp.html
} 
pensaram em desenhar um serviço de concierge em saúde Business to Business (B2B) mais completo, oferecendo para as empresas, além da plataforma, um serviço de orientação via call center com enfermeira, que permitisse atendimento básico para os funcionários da empresa. $\mathrm{O}$ serviço mostrou-se atrativo, e algumas organizações privadas logo aderiram ao programa. Um depoimento de uma cliente mostra como os serviços Business to Consumer (B2C) e B2B acabavam se complementando:

Quando eu perdi o plano de saúde, após a saída da empresa em que eu trabalhava, me vi sem chão para continuar com acompanhamento médico para saber dos medicamentos de uso contínuo que eu precisava tomar. Como eu tenho pressão alta, eu tinha que comprar remédios como o hidroclorotiazida, o captopril e o atenolol, o que significava pelo menos $\mathrm{R} \$ 100,00$ das minhas contas mensais. Com o Saútil, eu encontrei um posto de saúde próximo da minha casa, sem precisar percorrer filas e filas pela cidade, achei uma médica muito boa que me dá todo o atendimento de que eu preciso, e ainda descobri que podia retirar os medicamentos gratuitamente pelo SUS. Agora que consegui me reestabelecer e abrir meu próprio salão, consegui oferecer aos meus funcionários o Programa Com Você, para que todos nós possamos ter um amparo na saúde. (Mirna)

\section{Transformando-se em um negócio de impacto relevante}

Com o modelo de receitas definido e com a clareza da relevância de seu impacto social, Edgard e Fernando foram aparecendo cada vez mais na mídia e eventos do ecossistema de negócios de impacto que estava nascendo no Brasil. Era uma empresa que suscitava aplausos e a certeza de que era possível criar impacto social por meio de mecanismos de mercado.

Assim, no final de 2012, a Saútil foi uma das primeiras empresas selecionadas pela Vox Capital para receberem aporte financeiro, por meio de equity, ou seja, a Vox Capital pagaria o valor total em quatro parcelas e, em troca, teria uma participação da Saútil. Isso gerou uma revolução na vida da empresa e de seus sócios, que, pela primeira vez, passaram a trabalhar em tempo integral na organização e conseguiram estruturar um local de trabalho e equipe para que o sonho crescesse.

Outros clientes se interessaram pelo novo modelo de negócios, e a Saútil abriu um escritório na Vila Olímpia, com uma equipe de 22 pessoas, seis postos de atendimento e toda uma estruturação tecnológica para atender aos clientes (vide Organograma no Anexo 2). Em agosto de 2013, a Vox depositou a segunda parcela do investimento, apostando no potencial de crescimento da Saútil, que chegou a ter 120 mil acessos por mês em seu portal e mais de 20 mil usuários pagantes pela iniciativa privada.

A empresa aproveitou os recursos da Vox Capital e investiu na área administrativa, tecnologia, marketing, comercial e call center. Nesse momento, um dos maiores desafios da empresa foi montar um time de ponta. Com o rápido crescimento, surgiram muitas questões de relacionamento, uma rotatividade grande, com problemas de gestão. A empresa teve um avanço rápido da estrutura, e os desafios de gerenciar o negócio expandiram-se exponencialmente.

\section{Crise e mudança de rumo}

Em 2013, o Brasil começou a viver uma das principais crises política e econômica de sua história. Em 2014, a economia cresceu apenas 0,5\% e, em 2015, a queda do PIB foi de 3,8\%. Isso afetou as empresas de modo geral e veio como uma bomba para uma startup que dependia do sucesso das empresas clientes para sobreviver com a receita no B2B.

Com isso, os clientes que a Saútil havia adquirido em 2013 e 2014 estavam reduzindo suas vidas gerenciadas (ou seja, o número de funcionários servidos pela Saútil) e minguando a carteira de clientes. As empresas estavam demitindo, e os planos de saúde também começaram a perder usuários. Em 2014, a Saútil fez propostas comerciais na monta de mais de R 8 milhões, mas só 
conseguiu fechar contratos no valor total de $\mathrm{R} \$ 600$ mil, indicando um período bastante turbulento para a empresa.

Para receber a quarta parcela do investimento da Vox Capital, os sócios tinham que mostrar alternativas de modelos que pudessem alavancar a empresa. Os altos custos fixos inviabilizam a operação. Assim, em maio de 2014, a Saútil foi obrigada a demitir todos os funcionários, com a saída inclusive dos dois outros sócios que haviam se incorporado à organização.

Lá estavam Fernando e Edgard sozinhos novamente, tendo que encontrar um novo modelo de negócios viável para não deixar a empresa morrer prematuramente. A saída foi buscar outras alternativas ao modelo adotado até aquele momento. Assim, em junho de 2014, a Saútil começou a pivotar um novo modelo: oferecer serviços para iniciativa pública (Business to Government - B2G).

Para trabalhar com o Governo, a Saútil fez uma parceria com a Comunitas, uma organização da sociedade civil brasileira que tem como objetivo contribuir para o aprimoramento dos investimentos sociais corporativos e estimular a participação da iniciativa privada no desenvolvimento social e econômico do País.

A Comunitas trabalha com o conceito de parceria público-privada e conseguiu abrir as portas de algumas prefeituras para a Saútil. O primeiro município a realizar um contrato com a Saútil foi Pelotas/RS. O produto oferecido para a cidade era para facilitar o acesso à população às informações relativas aos serviços de saúde.

A Prefeitura de Pelotas implementou a solução da Saútil chamada Clique Saúde Pelotas (www.cliquesaudepelotas.com.br), em que era possível saber quais os medicamentos, vacinas, consultas e exames oferecidos na cidade, onde encontrá-los e como retirá-los. O serviço funcionava tanto no site do município, em smartphones, como também em totens espalhados pela cidade. Também estavam disponíveis na plataforma vários outros conteúdos ligados à saúde, os dados sobre as vacinas que devem ser tomadas em cada faixa etária e os locais disponíveis para isso.

O modelo trouxe novo fôlego para a Saútil, que viu no B2G uma saída para a dificuldade de superar o problema de monetização dos serviços. Em 2015, com o apoio da Comunitas, a Saútil começou a prospectar novas prefeituras pelo Brasil. Paraty foi a segunda cidade a implementar e oferecer o mesmo serviço (www.cliquesaude.pmparaty.rj.gov.br).

A venda B2G apresentava uma vantagem adicional ao modelo, pois o contato com as prefeituras permitiria melhorar ainda mais a base de dados da Saútil, com informações mais precisas de disponibilidade de estoques de medicamentos nos postos de saúde. No entanto, era um modelo sem recorrência de receitas, ou seja, o sistema era vendido apenas uma vez para a prefeitura e depois não havia uma segunda venda.

No modelo B2G, a Saútil buscava realizar propostas de até $\mathrm{R} \$ 80$ mil para não ter que participar da lei de licitações. No entanto, a Saútil, em alguns municípios, tinha que concorrer em licitações do Governo com outras empresas gigantes do ramo de tecnologia e que não eram especializadas nesse tipo de serviço, mas que poderiam oferecer produtos similares a um custo mais baixo. Por exemplo, em 2015, a empresa participou de uma cotação de preços para atender 10 municípios. A demanda havia surgido a partir da percepção de que o serviço da Saútil era realmente útil. Porém, a empresa perdeu a licitação para outras empresas de tecnologia, que ofereciam também outros serviços, como suporte de quatro anos de rede e hospedagem. A Saútil não tinha competitividade contra gigantes desse segmento.

Além disso, nesse momento, uma das maiores crises políticas atingiu o País, com os escândalos de corrupção e a operação Lava Jato ganhando espaço e força. Com isso, a empresa teve muitas dificuldades em divulgar e vender o projeto, e se viu novamente no dilema de como voltar a crescer.

\section{Futuras possibilidades}

Depois de cinco anos, Edgard e Fernando percebiam que tinham evoluído bastante, 
construído muitos ativos importantes para a sociedade, porém tinham a clareza de que fariam algumas coisas diferentes. A empresa viveu vários "saltos de galinha", sem nunca conseguir alçar um voo maior. Apesar de todas as dificuldades e crises atravessadas, os sócios continuavam acreditando no impacto social da Saútil e suas possibilidades de crescimento. O Anexo 1 mostra alguns dados de acesso à plataforma da empresa no final de 2016.

$\mathrm{O}$ modelo B2B, com call center, ainda tem um grande potencial. Os planos de saúde representam um custo relevante para as empresas, e a Saútil poderia ser uma alternativa interessante para que as empresas oferecessem algum atendimento aos seus funcionários, tendo uma melhor gestão de saúde a um custo reduzido.

Uma vertente diferente do B2B era um projeto iniciado em 2015 com uma grande empresa de varejo, em que a Saútil desenvolveria um aplicativo específico para atender mais de um milhão de representantes de venda. Esse modelo seria uma forma de atender uma base maior, com um intermediário divulgando a plataforma.

Outra alternativa de crescimento é o próprio B2G, que, apesar das dificuldades da crise e concorrência, tinha se provado como uma ferramenta relevante para o Governo e poderia ser escalável e ter um grande impacto social.

Os sócios acreditavam que, para ter mais sucesso, precisariam ter um foco maior. Um exemplo é que, mesmo sem investimentos, o site continuava com 60 mil acessos por mês. Todo o segredo estava na boa estruturação do produto, que, na visão deles, teria que ser mais "plug \& play" e não tentar vender vários produtos ao mesmo tempo (0800 dados, call center, geolocalização, consultoria em implementação etc.). Na visão dos sócios, a empresa não perdeu nenhuma oportunidade, mas, ao mesmo tempo, perdeu foco. A empresa teve muitas oportunidades de negócio, mas faltaram foco e clientes fortes para a sustentabilidade do negócio.

$\mathrm{O}$ ano de 2017 começaria em breve, e as incertezas político-econômicas eram ainda muito grandes. Assim, uma possibilidade que a dupla de sócios considerava era vender a empresa para outra organização, que poderia aproveitar a plataforma Saútil e outros ativos construídos ao longo dos anos, como aplicativos mobile, sistemas de acompanhamento de pacientes e outros, e acoplá-los a um serviço maior na área de saúde. Em 2016, três empresas mostraram-se interessadas em adquirir a Saútil, porém os valores ainda não eram suficientes, e as estratégias formuladas não foram assertivas para garantir o negócio.

A possibilidade de simplesmente fechar a empresa e buscar novos sonhos era algo que, a partir de 2017, tornou-se cada vez mais presente nas discussões dos sócios, que já estavam cansados de tantas tentativas frustradas. Conforme destacou Fernando, eram "muitos projetos que exigiram muito tempo, dinheiro, dedicação e que não deram em nada".

Nesse cenário, Fernando e Edgard deveriam decidir o futuro da Saútil, o que afetaria não apenas os dois, mas sua relação com a Vox Capital e diversos outros stakeholders que apoiaram a organização ao longo de sua jornada empreendedora. 


\section{Anexo 1. Dados da Saútil no final de 2016}

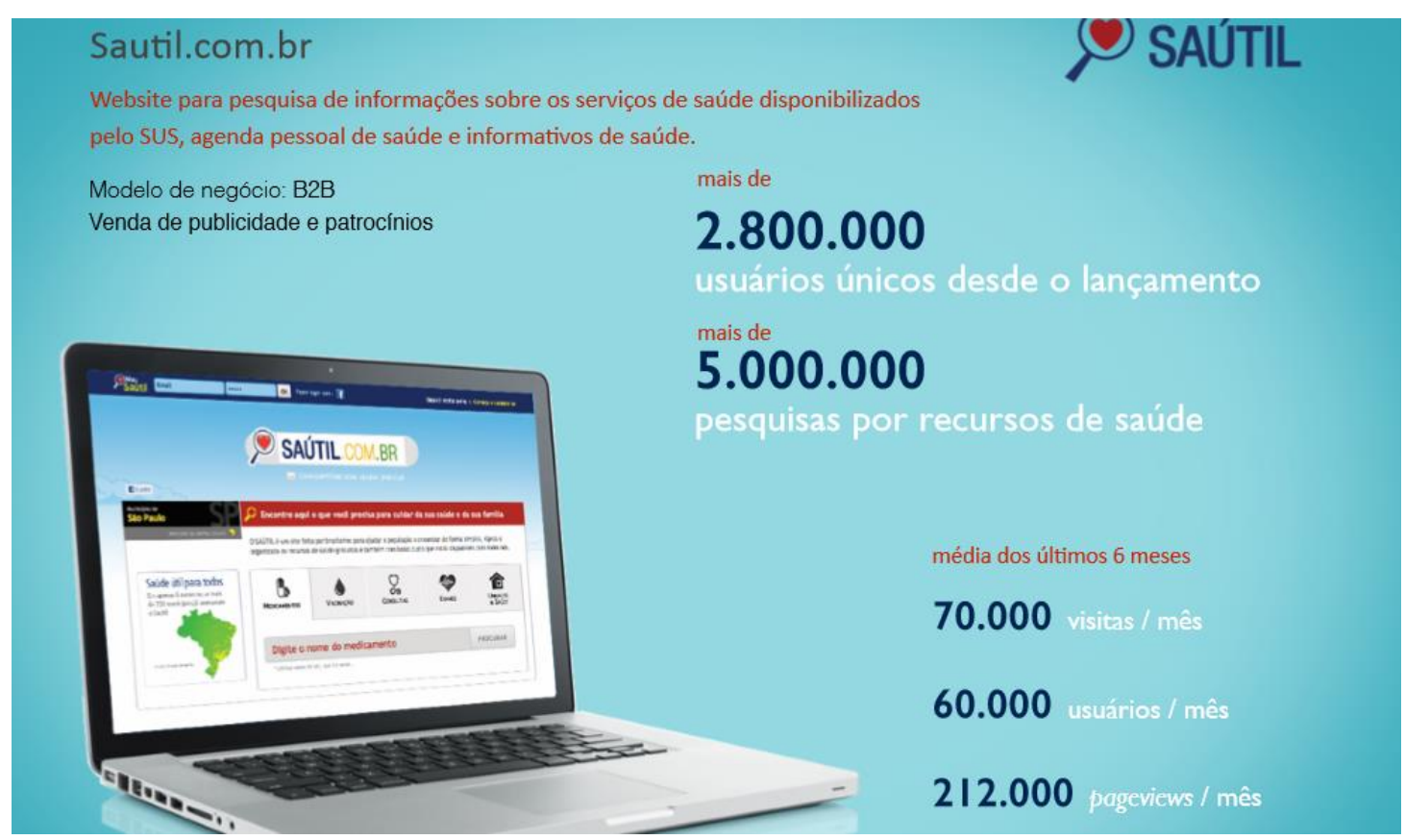

Anexo 2. Organograma Saútil - 2013

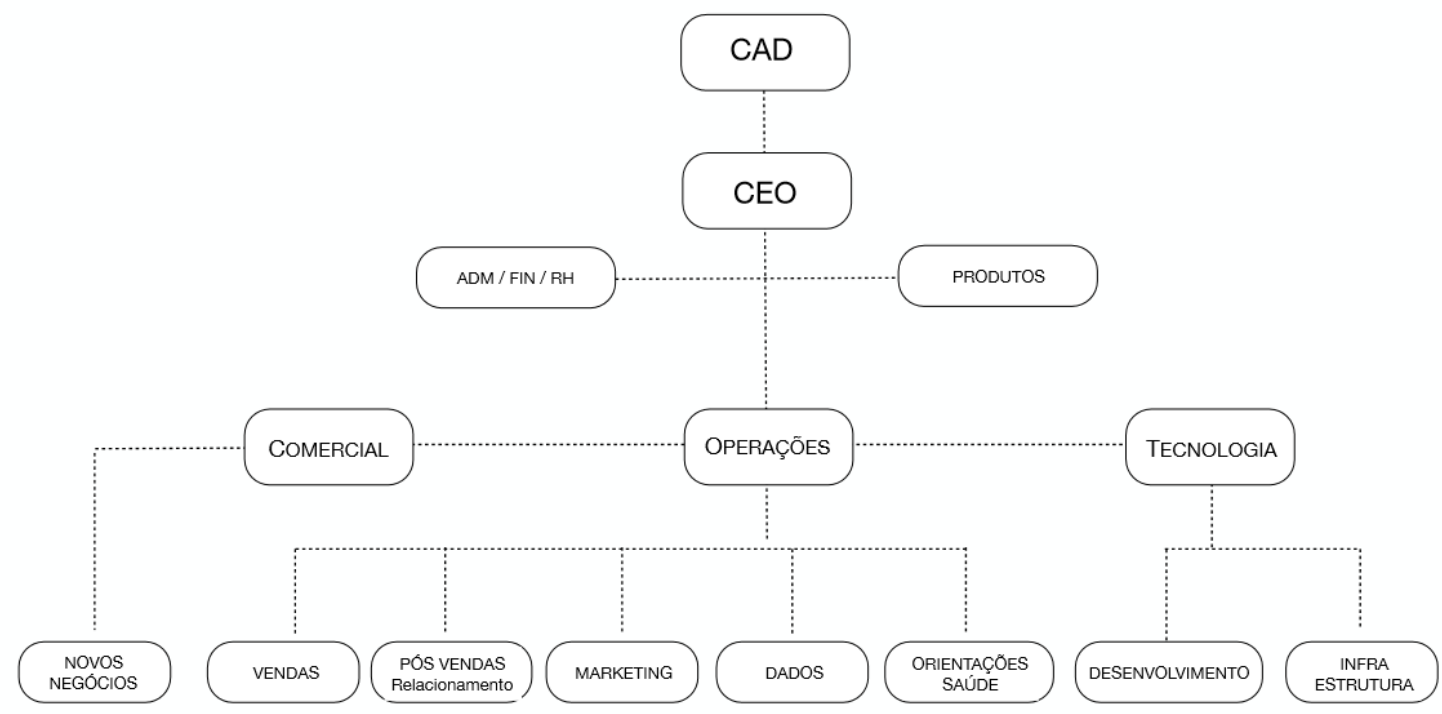

